\title{
ANALYSIS OF THE MAIN FACTORS INFLUENCING THE QUALITY OF WINE FROM MECHANICALLY HARVESTED GRAPES
}

\author{
Pietro Catania, Mariangela Vallone, Felice Pipitone
}

\section{Introduction}

The wine sector is going today through a period of severe crisis mainly due to the process of globalization in which all the countries producing wine have entered into fierce competition with each other. As a consequence, the achievement of the product on the market exclusively depends on a good value for money. One of the main factors affecting the cost of running the vineyard and, therefore, the final price of the wine is certainly the grape harvest. For the reasons given above this technique, used to be performed manually, is today impossible to support except that there would be the use of the harvesting machine [Clary 1990, Cardini 2004].

It's well known that the use of the harvesting machine has the limit of the production of must during harvest, that could reflect negatively on the quality of the final product. It depends on many factors including the physical-mechanical characteristics of the berry [Carrara 2007] and the frequency of the shakers of the harvesting machine. The frequency of shaking generally adopted is one that achieves the maximum harvest efficiency that means high work capacity and low grape juice production. It is well known that the shaking frequency (number of strokes / min), the same efficiency of the machine, can take different values depending on the speed of the harvesting machine; sometimes it is appropriate to express it in number of strokes per meter of advance of the machine.

The breaking of the harvested berries causes the trigger of some biochemical processes that negatively affect the merchandise and organoleptic characteristics of the wine and also its stability and then its qual-

Paper received 08.05.2009; accepted 23.11.2009

Pietro Catania, associate professor; Mariangela Vallone, researcher; FELICE PIPITONE, full professor; Department of Engineer and Agro-Forestry Technologies - University of Palermo, Viale delle Scienze ed.4 - 90128 Palermo, Italy. E-mail: p.catania@unipa.it

The authors have contributed equally to the work. ity [Nagel 1988]. Such negative effects are more evident when the ambient temperature is high and the time necessary to transfer the harvested grapes from the field to the wine cellar is excessive [Morris 1998, Ough 1971, Pockock 1998, Delgado 2005].

The aim of this work was to evaluate the influence of ambient factors on the quality of wines obtained from mechanically harvested grapes with different grape juice production.

\section{Materials and methods}

The research was carried out during the harvest 2007 in the wine farm Calatrasi located in Sancipirello, province of Palermo, Sicily. The vineyard was trained to hedgerow system with zinc-plated iron poles and five steel wires for conditioning the vegetation. The variety was Catarratto lucido (white berries), included in the Alcamo DOC (Designation of Origin).

The harvesting machine, by Pellenc company, model Smart System, was drawn by a New Holland tracked tractor $75 \mathrm{~kW}$ powered. The number of installed shakers was 12 , while the average speed of advance of the machine was $3.5 \mathrm{~km} / \mathrm{h}$.

Within the vineyard were the tests were performed, placed in proximity of the wine cellar of the farm, two parcels named A and B have been identified, extended 0.50 ha each to be harvested mechanically.

The control parameters of the harvesting machine were always kept constant except the shaking frequency that was equal to $400 \mathrm{~Hz}$ (plot A) and $450 \mathrm{~Hz}$ (plot B) in order to obtain two different values of the grape juice production. These are, in fact, two frequency values normally used during the mechanical harvest of grapes of the variety Catarratto.

In each plot the harvest efficiency was evaluated in terms of product quality by assessing the grape juice production.

The production of grape juice, that is the quantity of free juice on the whole mechanically harvested grapes, was determined by the ratio between the weight of the grape juice and the total weight of the sampled grapes. 


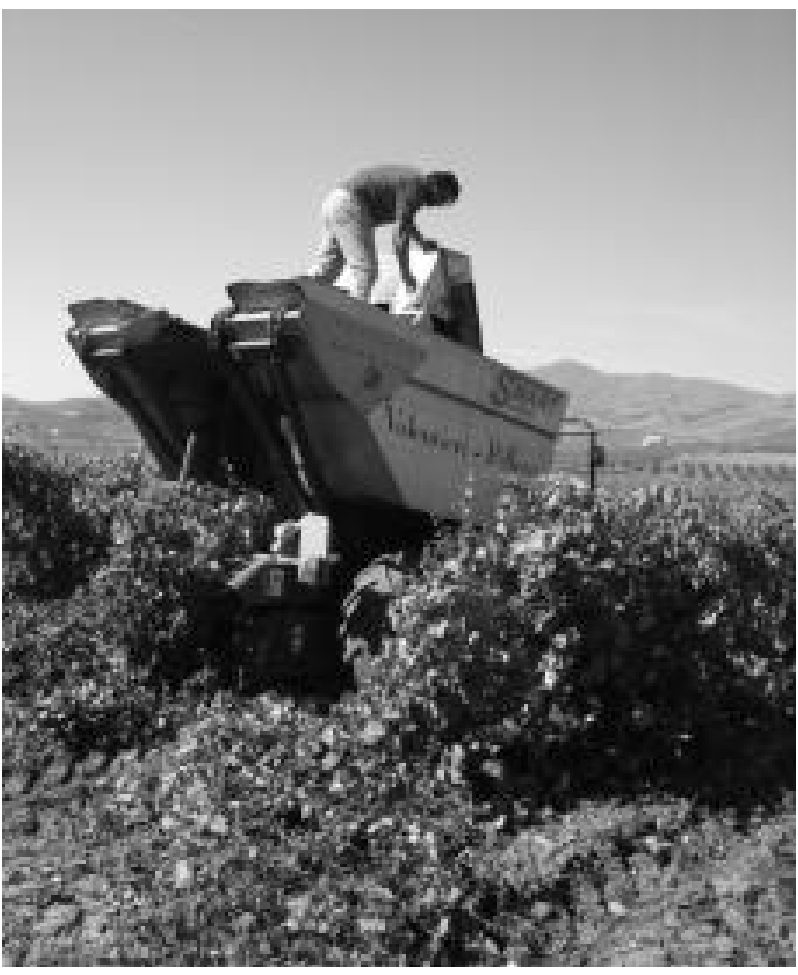

Fig. 1 - Samples of product drawn during the field tests.

During the harvest tests, 150 liters of product have been drawn in the plot $\mathrm{A}$ and 300 liters in $\mathrm{B}$. The product has been taken randomly on the whole plot through a container placed on the point of discharge of the product into the hopper of the harvesting machine (Figure 1).

The product, as it was taken, was poured into an insulated container and promptly transferred to the cellar for the subsequent analyses.

The grape juice production obtained during the tests was $15 \%$ in plot $\mathrm{A}$, where the shaking frequency applied was $400 \mathrm{~Hz}$, and $20 \%$ in B where the shaking frequency was $450 \mathrm{~Hz}$.

In addition, a sample of integral clusters of about $100 \mathrm{~kg}$ was taken from the two plots and transferred with boxes to the wine cellar.
In order to evaluate the influence of the grape juice production related to the time of exposure to the ambient conditions, 8 theses, 50 liters each, were carried out in the cellar from the samples obtained in the field, as shown in Table 1. In particular, the exposure to the ambient conditions was realized placing the samples in contact with the atmosphere and under the direct action of sunlight. The ambient temperature was $30^{\circ} \mathrm{C}$ and relative humidity $75 \%$.

In particular, the following theses were performed realizing three repetitions for each of them:

- tests 1 and 2, the control, with production of juice equal to zero (integral clusters, corresponding to manually harvested grapes) and exposure to the ambient conditions respectively of 3 and 6 hours;

- tests 3, 4, 5 and 6, different for the production of juice (15 and $20 \%$ ) and the time of exposure to the ambient conditions ( 3 and 6 hours);

- tests 7 and 8 added with potassium metabisulphite before the exposure to the ambient conditions $(0.1$ $\mathrm{g} / \mathrm{L})$, having the same production of juice $(20 \%)$ and different time of exposure to the ambient conditions, respectively 3 and 6 hours, in order to evaluate the efficacy of an antioxidant on the quality of the final product.

The choice of the above mentioned values of time of exposure to the ambient conditions, 3 and 6 hours, refers to the time of waiting in the field of the harvested grapes (3 hours at most) and its subsequent transfer to the cellar (further 3 hours at most).

After the exposure to the ambient conditions all the samples were subjected to a soft pressing and the obtained must was poured into micro winemaking tanks with a capacity of $50 \mathrm{~L}$ each, that were maintained at $18^{\circ} \mathrm{C}$ through the heat exchanger.

Then a micro wine-making was performed with the following operations: addition of potassium metabisulphite, addition of pectolitic enzyme, filtration through sieve, clarification, pouring off, inoculation of selected yeasts.

At the end of the fermentation the following parameters were determined: $\mathrm{pH}$, total and volatile acidity, alcohol, total dry extract and ashes.

\begin{tabular}{cccc}
\hline Test & $\begin{array}{c}\text { Grape juice } \\
(\%)\end{array}$ & $\begin{array}{c}\text { Time of } \\
\text { exposure to } \\
\text { the ambient } \\
\text { conditions } \\
\text { (h) }\end{array}$ & $\begin{array}{c}\text { Potassium } \\
\text { metabisulphite }\end{array}$ \\
\hline 1 & 0 & 3 & No \\
2 & 0 & 6 & No \\
3 & 15 & 3 & No \\
4 & 15 & 6 & No \\
5 & 20 & 3 & No \\
6 & 20 & 6 & Yes \\
7 & 20 & 3 & Yes \\
8 & 20 & 6 & \\
\hline
\end{tabular}

TABLE 1 - Characteristics of the different tests. 


\begin{tabular}{lllllllll}
\hline & \multicolumn{7}{c}{ Test } \\
\cline { 2 - 9 } & 1 & 2 & 3 & 4 & 5 & 6 & 7 & 8 \\
\hline pH & 3.22 & 3.23 & 3.18 & 3.14 & 3.18 & 3.15 & 3.24 & 3.24 \\
Total acidity $(g / L)$ & 7.13 & 7.10 & 6.98 & 7.35 & 7.20 & 7.20 & 7.05 & 6.53 \\
Volatile acidity $(g / L)$ & 0.14 & 0.14 & 0.10 & 0.07 & 0.09 & 0.12 & 0.12 & 0.12 \\
Alcohol $(\%)$ & 11.23 & 11.20 & 10.89 & 10.75 & 10.80 & 10.80 & 10.60 & 10.05 \\
Total dry extract $(g / L)$ & 20.30 & 20.29 & 21.10 & 21.35 & 22.45 & 21.90 & 20.60 & 17.90 \\
Ashes $(g / L)$ & 1.60 & 1.61 & 2.16 & 2.29 & 2.31 & 2.15 & 1.78 & 1.81 \\
\hline
\end{tabular}

TABLE 2 - Results of the physical-chemical analyses.

Afterwards, the stabilization was performed with refrigeration and the clarification with bentonite.

Finally, all the samples were subjected to spectrophotometric analyses through a spectrophotometer UV/vis with double ray in order to evaluate the total polyphenols using the reagent Folin Ciocalteu with absorbancy of $280 \mathrm{~nm}$ and $420 \mathrm{~nm}$ to determine the yellow dyes present when some oxidation process has begun. The spectrophotometric analyses were carried out for all the tests both before and after the fermentation.

All the data were subjected to a two-factor ANOVA and then the mean compared with Duncan's multiple comparison procedure (Statgraphics Centurion, Statpoint inc., 2005, USA).

\section{Results and discussion}

The results of all the laboratory analyses performed on the samples of must and wines were subjected to a two-factor analysis of variance with replication for the variables grape juice production and time of exposure to the ambient conditions and for the variables time of exposure and presence of antioxidant.

The analysis of variance performed on the physical-chemical analyses, performed 35 days after the end of the fermentation, did not show any statistically significant difference (tab. 2).

Table 3 shows the mean values of the total polyphenols obtained in the tests. The analysis of variance did

\begin{tabular}{|c|c|c|c|c|}
\hline & \multicolumn{2}{|c|}{ Must } & \multicolumn{2}{|c|}{ Wine } \\
\hline \multirow[t]{2}{*}{ Test } & $\begin{array}{r}\text { Total } p c \\
28\end{array}$ & $\begin{array}{l}\text { phenols } \\
\text { s } \\
\text { nm }\end{array}$ & Total p & $\begin{array}{l}\text { yphenols } \\
\text { nm }\end{array}$ \\
\hline & mean & st.dev. & mean & st.dev, \\
\hline 1 & 0.3243 & 0.0571 & 0.4459 & 0.0739 \\
\hline 2 & 0.3244 & 0.0582 & 0.4460 & 0.0736 \\
\hline 3 & 0.3293 & 0.0712 & 0.4918 & 0.0424 \\
\hline 4 & 0.3743 & 0.0914 & 0.5172 & 0.0772 \\
\hline 5 & 0.3765 & 0.0589 & 0.5220 & 0.0938 \\
\hline 6 & 0.3995 & 0.0687 & 0.5351 & 0.1229 \\
\hline 7 & 0.3315 & 0.0642 & 0.5010 & 0.1112 \\
\hline 8 & 0.3464 & 0.0660 & 0.5140 & 0.0331 \\
\hline
\end{tabular}

TABLE 3 - Total polyphenols values for must and wine samples. not show any statistically significant difference at the 95\% confidence level both for must and wine.

With reference to the yellow dyes, the ANOVA showed statistically significant differences among the means so that they were compared with Duncan's multiple comparison procedure (tabs 4 and 5). Moreover, the values of absorbancy of $420 \mathrm{~nm}$ obtained both for the samples of must and wine are higher than the value found in literature for similar varieties, (Chardonnay, respectively 0.0196 and 0.104, Nagel and Graber, 1988).

Table 4 shows that, both in must and in wine, there are no statistically significant differences between test 1 and 2 .

With reference to the must samples, tests 3, 4, 5 and 6 show statistically significant differences both among them and among tests 1 and 2. As a consequence, both grape juice production and time of exposure to the ambient conditions influences the colour of must having an increase of about $21 \%$ in the mean values going from 3 to 6 hours of exposure to the ambient conditions.

Furthermore, for the same exposure time, the increase of grape juice from 15 to $20 \%$ results in an increase in the values of the yellow dyes of the must of about $63 \%$.

Moreover, we have that the mean values of tests 5 and 6 , having $20 \%$ of grape juice, are respectively higher about 31 and 38 times than test 1 and 2, with no juice production.

\begin{tabular}{|c|c|c|c|c|}
\hline \multirow{5}{*}{ Test } & \multicolumn{2}{|c|}{ Must } & \multicolumn{2}{|c|}{ Wine } \\
\hline & \multirow{2}{*}{\multicolumn{2}{|c|}{$\begin{array}{c}\text { Yellow dyes } \\
\text { abs }\end{array}$}} & \multirow{3}{*}{\multicolumn{2}{|c|}{$\begin{array}{c}\text { Yellow dyes } \\
\text { abs } \\
420 \mathrm{~nm}\end{array}$}} \\
\hline & & & & \\
\hline & \multicolumn{2}{|c|}{$420 \mathrm{~nm}$} & & \\
\hline & mean & st.dev. & mean & st.dev. \\
\hline 1 & $0.0064 \mathrm{e}$ & 0.0007 & $0.0700 \mathrm{~d}$ & 0.0029 \\
\hline 2 & $0.0065 \mathrm{e}$ & 0.0068 & $0.0710 \mathrm{~d}$ & 0.0030 \\
\hline 3 & $0.0720 \mathrm{~d}$ & 0.0029 & $0.1650 \mathrm{c}$ & 0.0207 \\
\hline 4 & $0.0916 \mathrm{c}$ & 0.0016 & $0.1770 \mathrm{c}$ & 0.0131 \\
\hline 5 & $0.1970 \mathrm{~b}$ & 0.0052 & $0.2800 \mathrm{~b}$ & 0.0163 \\
\hline 6 & $0.2467 \mathrm{a}$ & 0.0198 & $0.3270 \mathrm{a}$ & 0.0216 \\
\hline
\end{tabular}

Note: Different letters in the column denote a statistically significant difference at the $95.0 \%$ confidence level.

TABLE 4 - Results of Duncan's multiple comparison procedure for the yellow dyes values for must and wine samples (tests 1-2-3-4-5-6). 


\begin{tabular}{|c|c|c|c|c|}
\hline \multirow{5}{*}{ Test } & \multicolumn{2}{|c|}{ Must } & \multicolumn{2}{|c|}{ Wine } \\
\hline & \multirow{2}{*}{\multicolumn{2}{|c|}{$\begin{array}{c}\text { Yeliow dyes } \\
\text { abs }\end{array}$}} & \multirow{3}{*}{\multicolumn{2}{|c|}{$\begin{array}{c}\text { Yellow dyes } \\
\text { abs } \\
420 \mathrm{~nm}\end{array}$}} \\
\hline & & & & \\
\hline & \multicolumn{2}{|c|}{$420 \mathrm{~nm}$} & & \\
\hline & mean & st.dev. & mean & st.dev. \\
\hline 5 & $0.1970 \mathrm{~b}$ & 0.0052 & $0.2800 \mathrm{~b}$ & 0.0163 \\
\hline 6 & $0.2467 \mathrm{a}$ & 0.0198 & $0.3270 \mathrm{a}$ & 0.0216 \\
\hline 7 & $0.0944 d$ & 0.0042 & $0.1680 \mathrm{~d}$ & 0.0111 \\
\hline 8 & $0.1299 \mathrm{c}$ & 0.0101 & $0.2060 \mathrm{c}$ & 0.0167 \\
\hline
\end{tabular}

Note: Different letters in the column denote a statistically significant difference at the $95.0 \%$ confidence level.

TABLE 5 - Results of Duncan's multiple comparison procedure for the yellow dyes values for must and wine samples (tests 5-6-7-8).

With reference to the mean values of the yellow dyes of wine, it comes out that the time of exposure to the ambient conditions of 3 and 6 hours with a grape juice of $15 \%$ (tests 3 and 4 ) does not affect the future wine's colour.

On the contrary, statistically significant differences have been obtained between tests 5 and 6 with a grape juice of $20 \%$ and an increase of about $15 \%$ in the mean values of the yellow dyes. Finally, statistically significant differences have been obtained in tests 3 and 4 compared with tests 5 and 6 with a $41 \%$ increase of the yellow dyes going from test 3 to test 5 and a $45 \%$ increase from test 4 to test 6 .

Finally, it emerges that under the same conditions of time of exposure, the values of yellow dyes of tests 5 and 6 , having a grape juice of $20 \%$, are respectively 4 and 5 times higher than tests 1 and 2 having no grape juice production.

Table 5 shows that among tests 5, 6, 7 and 8, all of them having a grape juice of $20 \%$, there are statistically significant differences both for must and for wine.

In particular, it is clear that for the samples having time of exposure of 3 hours, the antioxidant allows to reduce the yellow dyes by $52 \%$ in must and $40 \%$ in wine (tests 5-7). Instead, with time of exposure of 6 hours the yellow dyes decrease by $47 \%$ in must and $37 \%$ in wine (tests 6-8). From here it comes out that the action of the antioxidant in terms of yellow dyes is more effective when the time of exposure is lower, both for must and wine.

\section{Conclusions}

The aim of this work was to study the main factors influencing the quality of wine from mechanically harvested grapes; some interesting conclusions can be drawn from it.

In particular, the results show that the quality of wine from mechanically harvested grapes is influenced both by the grape juice production and by the time of waiting before the wine-making.

Grape juice production, that can be limited apply- ing a rational control of the harvesting machine, should not be above $15 \%$ with ambient temperature equal to or higher than $30^{\circ} \mathrm{C}$. With higher values it's appropriate to intervene in the field adding an antioxidant to the harvested grapes.

With reference to the time of exposure to the ambient conditions of the harvested grapes, the time of waiting in the field and transfer to the cellar should be lower than 3 hours in order to obtain wines of quality. If this is not possible, it is appropriate to intervene, even in this case, with an antioxidant.

\section{References}

Cardini F., De Biasi C., Falcetti M., Campostrini F. Scelta dell'epoca vendemmiale. L'Informatore Agrario, 2004, 30, 39-48.

Carrara M., Catania P., Pipitone F., Vallone M., Salvia M. Assessment of the pedicel detaching and crushing forces of grape berries to determine the right mechanical harvesting period. Rivista di Ingegneria Agraria, 2007, 3, 33-37.

Clary C.D., Steinhauer R.E., Frisinger J.E., Peffer T.E. Evaluation of machine-vs. hand-harvested Chardonnay. American Journal of Enology and Viticulture, 1990, 41, 176-181.

Delgado A.E., Sun D.W., Rubiolo A. C. Thermal physical properties of foods. In Thermal Food Processing: New Technologies and Quality Issues, 2005, 1-32, D.-W. Sun, ed. Florida, USA: Dekker/CRC Press.

Morris J.R. Factors influencing grape juice quality. HortTechnology, 1998, 8, 471-478.

Nagel C.W., Graber W.R. Effect of must oxidation on quality of white wines. American Journal of Enology and Viticulture,1988, 39, 1-4.

Ough C.S., Berg H.W. Simulated mechanical harvest and gondola-transport. Effect of temperature, atmosphere, and skin-contact on chemical and sensory qualities of white wines. American Journal of Enology and Viticulture,1971, 22, 194-198.

Pocock K.F., Waters E.J. The effect of mechanical harvesting and transport of grapes, and juice oxidation, on the protein stability of wines. Australian Journal of Grape and Wine Research, 1998, 4, 136-139.

\section{SUMMARY}

The present paper consisted in the study of the main factors influencing the quality of wines produced from mechanically harvested grapes.

In particular, 8 samples of grape clusters were examined, different for the harvesting technique, grape juice production, time of exposure to the ambient conditions and addition of an antioxidant

The results confirm that the control of some parameters such as grape juice production, ambient temperature and time of exposure of the harvested grapes to the ambient conditions is essential in order to obtain wines of quality from mechanically harvested grapes.

Keywords: mechanical harvest, grape juice, quality, wine. 